\title{
International Journal of
}

\section{Computer Network and Information Security}

\section{Kol.5}

No. 8 June 2013

\section{IJCNIS KoI.5} Http:// www.mecs-press .org Vol. 5 No.8 June 2013
$+$

Modern Education

and Computer Science PRESS 


\section{International Journal of Computer Network and Information Security (IJCNIS)}

ISSN Print: 2074-9090, ISSN Online: 2074-9104

Volume 5, Number 8, June 2013

\section{Contents}

\section{REGULAR PAPERS}

Analysis of the SYN Flood DoS Attack

Mitko Bogdanoski,Tomislav Shuminoski,Aleksandar Risteski

MUSIC 2D-DOA Estimation using Split Vertical Linear and Circular Arrays

Yasser Albagory,Amira Ashour

Information Leakage Prevention Using Virtual Disk Drive

Tarek S. Sobh

A Novel Solution for Discriminating Wormhole Attacks in MANETs from Congested Traffic using RTT and 28 Transitory Buffer

Maria Sebastian,Arun Raj Kumar P.

GSM Base Stations Location Monitoring using Geographic Information System

Kuboye B. M.,Dada O. A.,Akinwonmi F. C.

Performance Analysis of Route Discovery by Cross Layer Routing Protocol- RDCLRP

Mehajabeen Fatima,Roopam Gupta,T.K.Bandhopadhyay

Establishing Inter Vehicle Wireless Communication in Vanet and Preventing It from Hackers

M. Milton Joe,R.S. Shaji,K. Ashok Kumar

Geographic Load Balanced Routing in Wireless Sensor Networks 